\title{
Chapter 28 \\ Measures of Ageism in the Labour Market in International Social Studies
}

\author{
Liili Abuladze and Jolanta Perek-Białas
}

\subsection{Introduction}

Because the population is ageing, the workforce is also ageing, and ageism in the workplace has become increasingly evident. Measuring and analysing ageist attitudes, values, and perceptions among the general population is a more common practice than researching ageism in the workplace or in the labour market (e.g., Ayalon 2013). However, there are some good examples of research on ageism in the labour market (for some general studies see Phillipson 2004; Taylor and Walker 1998).

It is important to acknowledge that the lives of older adults and their ageing experiences are not fixed but fluid, dialectical, contextual, and changeable through human actions (Calasanti 1996). This is especially important in the labour market context, because of the tendency of ascribing fixed or inherent characteristics to older working people that may hinder working. A more detailed picture of older workers and retirement will help lead to a better understanding of many facets of ageism. Combining research on ageism in general and research on ageism in the labour market could help inspire new theoretical frameworks on these issues.

In the current chapter, ageism is firstly seen in prejudiced attitudes towards older people and their participation in the labour force. Ageism can be encountered in job seeking and hiring practices (Karpińska et al. 2011), in the workplace (Duncan 2003), in retention of workforce (Perek-Białas and Turek 2012), and in retirement

\footnotetext{
L. Abuladze $(\bowtie)$

Estonian Institute for Population Studies, Tallinn University, Tallinn, Estonia

e-mail: liili@tlu.ee

J. Perek-Białas

Jagiellonian University, Krakow, Poland

Warsaw School of Economics, Warsaw, Poland

(C) The Author(s) 2018

L. Ayalon, C. Tesch-Römer (eds.), Contemporary Perspectives on Ageism, International Perspectives on Aging 19,

https://doi.org/10.1007/978-3-319-73820-8_28
} 
practices (McNair 2006). Ageism in the labour market participation phase can manifest in cases when older people are not re-trained for or considered for jobs that require new types of skill sets in specific economic sectors, such as the high-tech or IT industries.

Much of the debate about older people in the labour market context centres on their productivity decline (Skirbekk 2004). Employers usually value the loyalty and experience of older workers, but often have doubts about their adaptability and learning capability (Solem 2015; Turek and Perek-Białas 2013). Specifically, managers often see older workers as resistant to innovation (Conen et al. 2011a; Henkens 2005). Such prejudices become even more of a concern given the technological advancements and emergence of the digital market in Europe, and may hold older adults back from acquiring new skills and knowledge necessary for new types of tasks. In addition to hindering renewal of skills at current workplaces or making training opportunities less accessible for older people, this could also result in difficulties to find a job (which is related to hiring practices). More communication and frequent contact with older workers, especially at the leadership or managerial level of the workplace, have been shown to help dissolve managers' negative stereotypes of older workers (Henkens 2005; Solem 2015).

Another form of ageism in the labour market, which may be country-specific, is structural ageism, stemming from fixed or in some cases even mandatory ${ }^{1}$ retirement ages that prohibit or make it difficult for people to continue working after a certain age (O'Dempsey and Beale 2011). These are situations where statutory retirement age is coupled with mandatory retirement - that is, a country's policies or legislations do not allow a person to work and receive a pension at the same time (OECD 2013; Sonnet et al. 2014). Some tax and benefit arrangements were identified previously as incentives for early retirement in most of the so-called industrialised countries - these operated as a way to allow younger generations to enter the labour market (Duval 2003; Blöndal and Scarpetta 1997). However, several countries have declared these incentives and practices unsustainable, and are reviewing and reforming these arrangements, for example by rising retirement ages. Although retirement age should usually correspond to population health developments and availability of national resources, it can be considered a form of ageism when it creates a barrier to employment. Moreover, such retirement age limits might be partly creating ageist attitudes in people, reinforcing the view of older people as fragile and non-capable after a certain age.

Ageism in the labour market can be intertwined with other discriminatory attitudes towards gender, ethnicity or race, and class (Crenshaw 1991; Jyrkinen and Mckie 2012). Additionally, differences in countries' workplace ageism depend on contextual and historical backgrounds that impact people's attitudes and values, and consequently the results of surveys that are taken in those countries. We explore

\footnotetext{
${ }^{1}$ Mandatory retirement age is a specific age at which the employee must retire. Several EU countries have mandatory retirement ages for specific sectors (O'Dempsey and Beale 2011). Fixed retirement age is defined for the purpose of this paper as simply being fixed at some level in a country as opposed to having a flexible retirement age system, such as in Sweden.
} 
international surveys that could be used for studying ageism in the labour market, and discuss their main attributes in the evaluation of measures, keeping in mind the target population, definition of old age, and a variety of country contexts. An international comparison of measures allows for a detailed evaluation of the performance of indicators across cultures, and international comparisons of measures of ageism in the labour market may provide insights into whether a country's position is an outlier or part of a regional pattern.

The following section gives an overview of the surveys chosen for our chapter. The third section presents descriptive results of country positions on five aspects of ageism in the labour market. This is followed by a discussion of the findings. Finally, the last section provides recommendations for researching ageism in the labour market using existing tools (measures as well as surveys).

\subsection{Comparative Surveys}

We look at how ageism in the labour market as a stereotype, attitude, or experience has been measured in international (mostly European) cross-country social surveys in order to evaluate available research tools. We searched all measures that reflected aspects of job seeking or hiring, workplace experiences or attitudes, retention of workers, retirement practices, skill renewal, and the qualities or characteristics ascribed to older workers.

The surveys were chosen based on the following criteria:

- They had information on individuals' (in some cases employers' or managers') self-reported experiences or attitudes regarding age in labour-market related issues;

- They were international/European cross-country surveys of the general population;

- Or they were international/European surveys that focused on the labour market or workplace context.

We examined the following surveys:

- The European Social Survey

- The World Values Survey

- Eurobarometer

- The Generations and Gender Survey

- The Survey of Health, Ageing and Retirement in Europe

- The European Union Labour Force Survey

- The European Company Survey

- The European Working Conditions Survey

- The Activating Senior Potential in Ageing Europe

These surveys were targeted at individuals or employers. All of the surveys were carried out in several countries which makes international comparisons and 
measures of ageism in the labour market possible. Also, most of these surveys have been established as regular data collecting infrastructures, and some of them specialise in studying the labour market context. These surveys are usually representative of the total population, thus making it possible to compare different population group experiences with ageism. More information on the sampling procedures and questionnaire methodologies of each survey can be found on their websites or in relevant publications.

Two surveys - the European Social Survey and the World Values Survey-are specifically aimed at charting the development of attitudes and values. Correspondingly, we found a large number of indicators in these surveys that measure ageist attitudes in the labour market. These indicators were mapped in special ageism modules: in round 4 of the European Social Survey (2008) and in round 6 of the World Values Survey (2010-2014). Similarly, Eurobarometer maps public opinion on various issues, including age-related attitudes in working environments. Discrimination-related questions were asked in 2006, 2009, 2012, and 2015. This survey regularly asks the opinion of around 1000 people aged 15 and above in each EU member state and EU candidate country.

The Generations and Gender Survey aims to study family relations and dynamics by interviewing people aged 18-79. It contained two indicators of ageism in the labour market that could be included in the analysis (from waves 1 and 2). Overall, 18 European countries and Australia have been part of the Generations and Gender Survey, a panel study that is carried out every 3 years in most of the participating countries. The fieldwork in different countries was carried out between 2002 and 2013.

The Survey of Health, Ageing and Retirement in Europe is a longitudinal survey of European countries interviewing people aged 50 and older every 2 years since 2004 on a wide range of topics, including work and retirement. The number of countries has varied, but steadily increased over the years, and the whole European Union is covered from the seventh survey round (since 2017). This survey is an offspring of the Health and Retirement Study that was started in the US.

The European Union Labour Force Survey is an annual survey of the European Union working-age population (15-74 year olds) carried out in all European Union countries. We mention this survey because we found one question from the questionnaire of the Estonian Labour Force Survey (2009-2014) that addressed ageist hiring practices. $^{2}$

There are also a number of surveys mapping employers' perspectives or employees' working environments, such as the European Company Survey, the European Working Conditions Survey (both carried out by Eurofound), and Activating Senior Potential in Ageing Europe, funded under the Seventh EU Framework Programme (Conen et al. 2011a).

\footnotetext{
${ }^{2}$ Unfortunately, we did not find similar questions in the surveys of other countries. Therefore, at the time of writing this paper, it was not possible to make a comparative analysis based on this indicator.
} 
The first European Company Survey was carried out in 2004-2005 and included 21 countries: 15 'old' European Union Member States, as well as Cyprus, the Czech Republic, Hungary, Latvia, Poland, and Slovenia. The second European Company Survey was carried out in 2009 and included 30 countries: the $27 \mathrm{EU}$ member states, Croatia, the Former Yugoslav Republic of Macedonia, and Turkey. The third time the survey was carried out was in 2013 and it included companies from 32 countries - the 27 European Union member states and Croatia, the former Yugoslav Republic of Macedonia, Iceland, Montenegro, and Turkey. The European Working Conditions Survey, which has been running since 1991, maps the working conditions and work environments of employees and self-employed people in Europe. The sixth wave was conducted in 2015 and included the 28 European Union countries, as well as Norway, Switzerland, Albania, the former Yugoslav Republic of Macedonia, Montenegro, Serbia, and Turkey.

The Activating Senior Potential in Ageing Europe project aimed at mapping employers' views and practices regarding older workers (ages 50-70) in ageing societies, and whether employers' views and organisational policies correspond to governments' policies (Conen et al. 2011a), providing a valuable source of studying ageism in the labour market. In total, more than 6800 employers were interviewed in Denmark, Germany, France, Italy, Poland, the Netherlands, the United Kingdom, and Sweden in this survey. We selected two questions from Activating Senior Potential in Ageing Europe to present here. These questions can be used as examples of measuring direct ageist attitudes of employers.

We calculated the prevalence of ageism per measure for each country and the mean of each indicator. The choice for a cut-off point indicating when a relatively large proportion of people could be identified as engaging in ageist behaviour or having ageist attitudes according to a specific measure in each country was based on the standard deviation of the mean. The results indicate ageism towards older people. Other potential indicators for which we could not present findings, but which could be valuable for research on ageism in the labour market are discussed in a separate section (Sect. 28.3.6). The overview and list of measures in Sect. 28.3 is followed by an evaluation of the observed measures (Sect. 28.4) and recommendations for researching ageism in the labour market (Sect. 28.5). The evaluation of findings led us to develop a taxonomy of measures, which we follow in outlining our recommendations for future research of ageism in the labour market.

\subsection{Measures of Ageism in the Labour Market}

We identified 18 of the most relevant measures from seven international (mostly European) large-scale population surveys and from one employers' survey that included eight European countries. All measures were self-reported. Seventeen indicators measured ageist attitudes and perceptions in the labour market (either from the employees' or the employers' perspective) or attitudes and perceptions about ageism in the labour market. One indicator measured the experience of 
structural ageism in the labour market (see Table 28.1). We chose these measures based on their explicit mention of an age-related word in the question in relation to any aspect of the labour market (contribution to the economy in general, labour market entry or exit, retaining workforce, workplace, colleagues, etc.). The most common age-related word was either a specific age number (e.g., 30, 70, 20s, 40s) or a relative indication of age, such as "young" or "old." The measures were grouped into five broad categories based on their focus:

- Workforce recruitment and/or retention,

- Performance,

- Training,

- Interaction with older colleagues,

- Structural ageism.

Most of the measures fell into the first two categories.

This chapter presents the results of international descriptive comparisons of the 18 measures grouped into five themes. Countries that had ageist attitudes or practices were chosen based on their results reaching above or below the standard deviation of the mean. This was true with the exception of one indicator from the Activating Senior Potential in Ageing Europe survey ("At what age would you say a person is too old to be working $20 \mathrm{~h}$ or more per week?"), as well as for the Eurobarometer indicator ("Regardless of whether you are actually working or not, please tell me, using a scale from 1 to 10 , how comfortable you would feel if one of your colleagues at work belonged to each of the following groups: a person over 60 years; a person under 25 years"). In case of the Activating Senior Potential in Ageing Europe indicator, the cut-off point was chosen to be age 65 . In the case of the Eurobarometer indicator, the difference between responses regarding younger and older age groups was calculated. We focus on ageism towards older age groups, hence, even if some questions were asking about younger age groups, we present the results that indicate ageism towards older adults.

\subsubsection{Recruitment and/or Retention of the Workforce}

One question from the European Social Survey used a specific age range to ask about people's concerns about employers' age-related preferences ("How worried are you that employers prefer people in 20 s rather than in their 40 s or above?"), and could be used as an indicator of perceived ageism of employers when recruiting or retaining workforce. A question from the Generations and Gender Survey that also specifically contrasted younger and older members of the workforce could also be used as a measure of general views of the employability of older people and is thus grouped under the category of recruitment and/or retention of workforce ("When jobs are scarce, younger people should have more right to a job than older people"). An important distinction between these two questions is that the latter reflects ageist views of the respondents themselves, not their experience or perception of ageist 


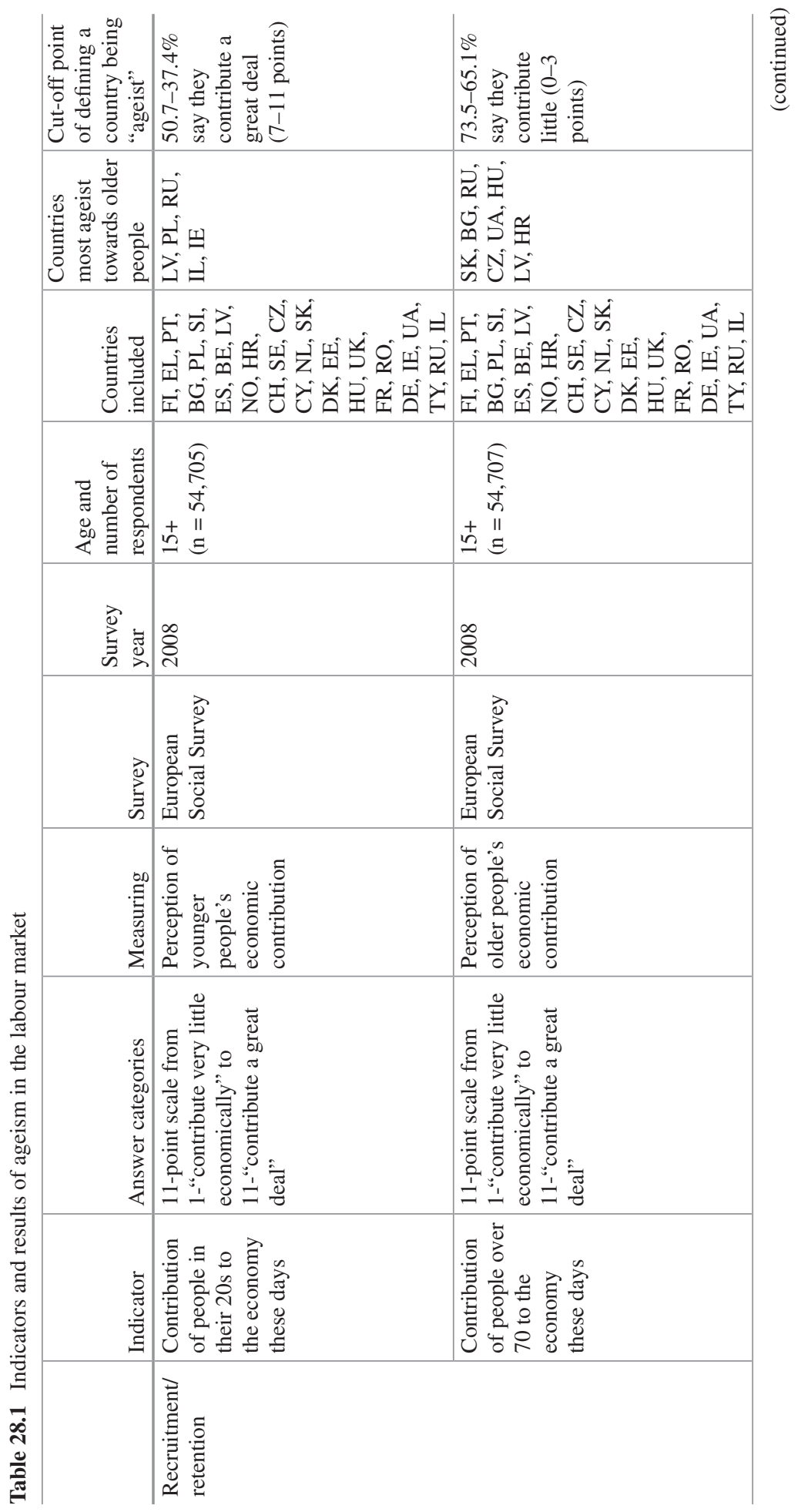




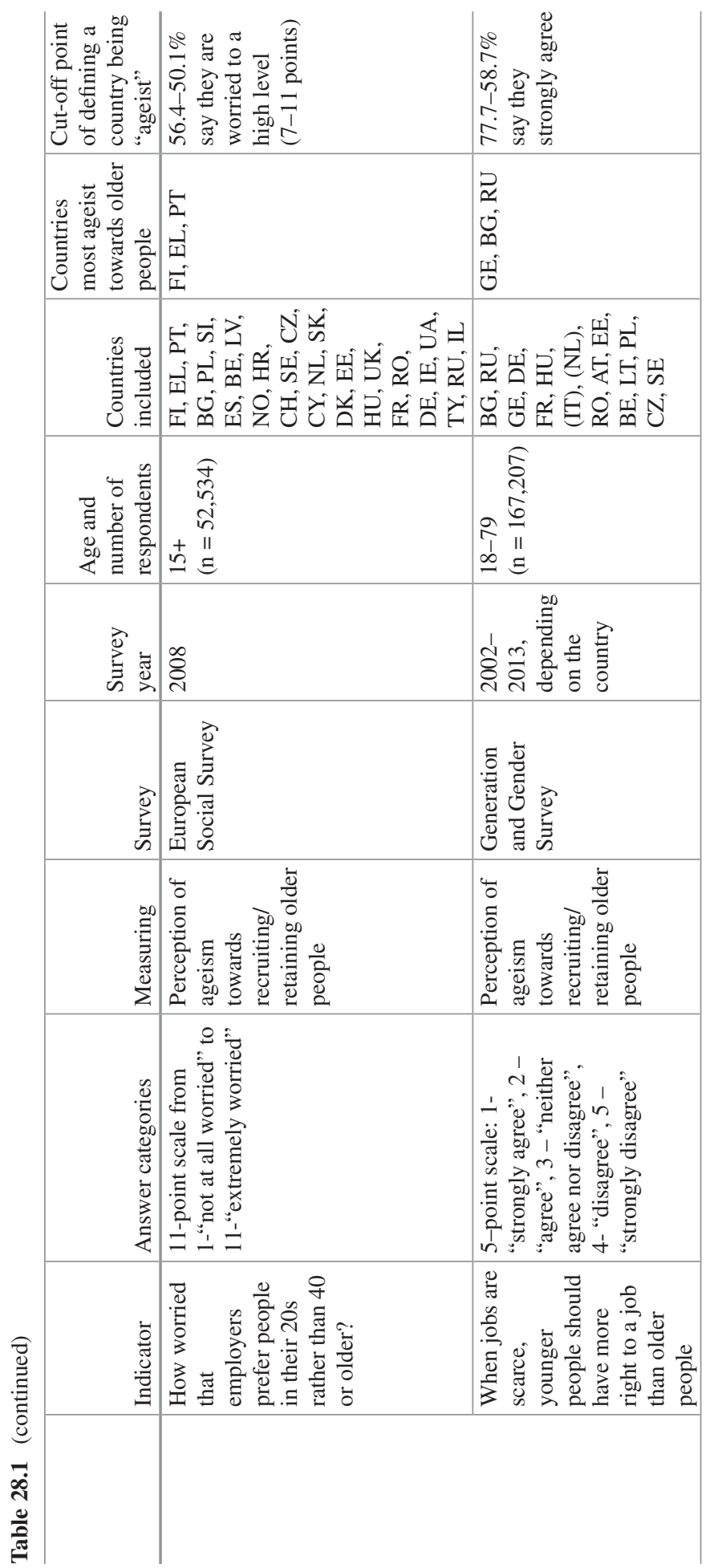




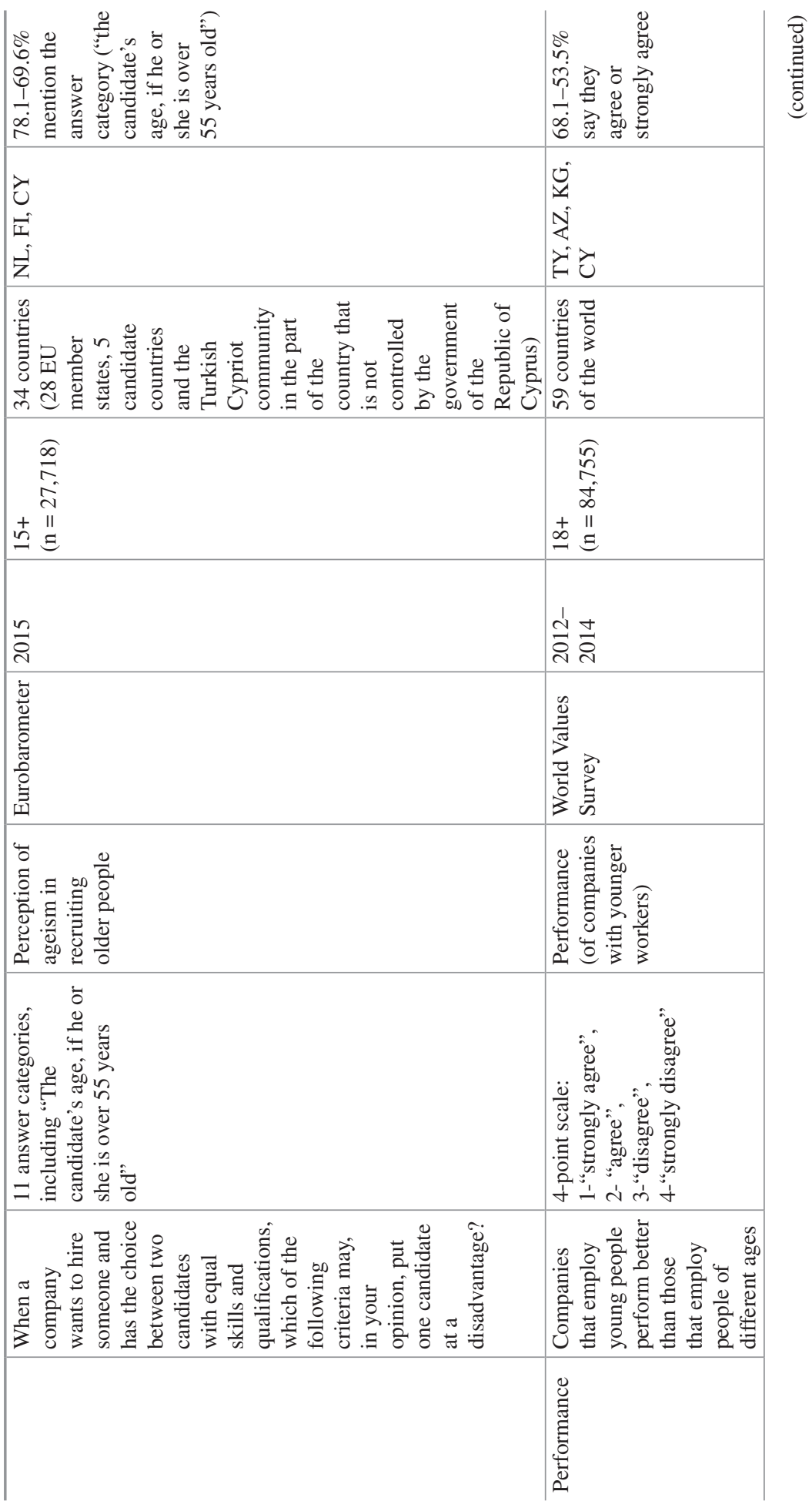




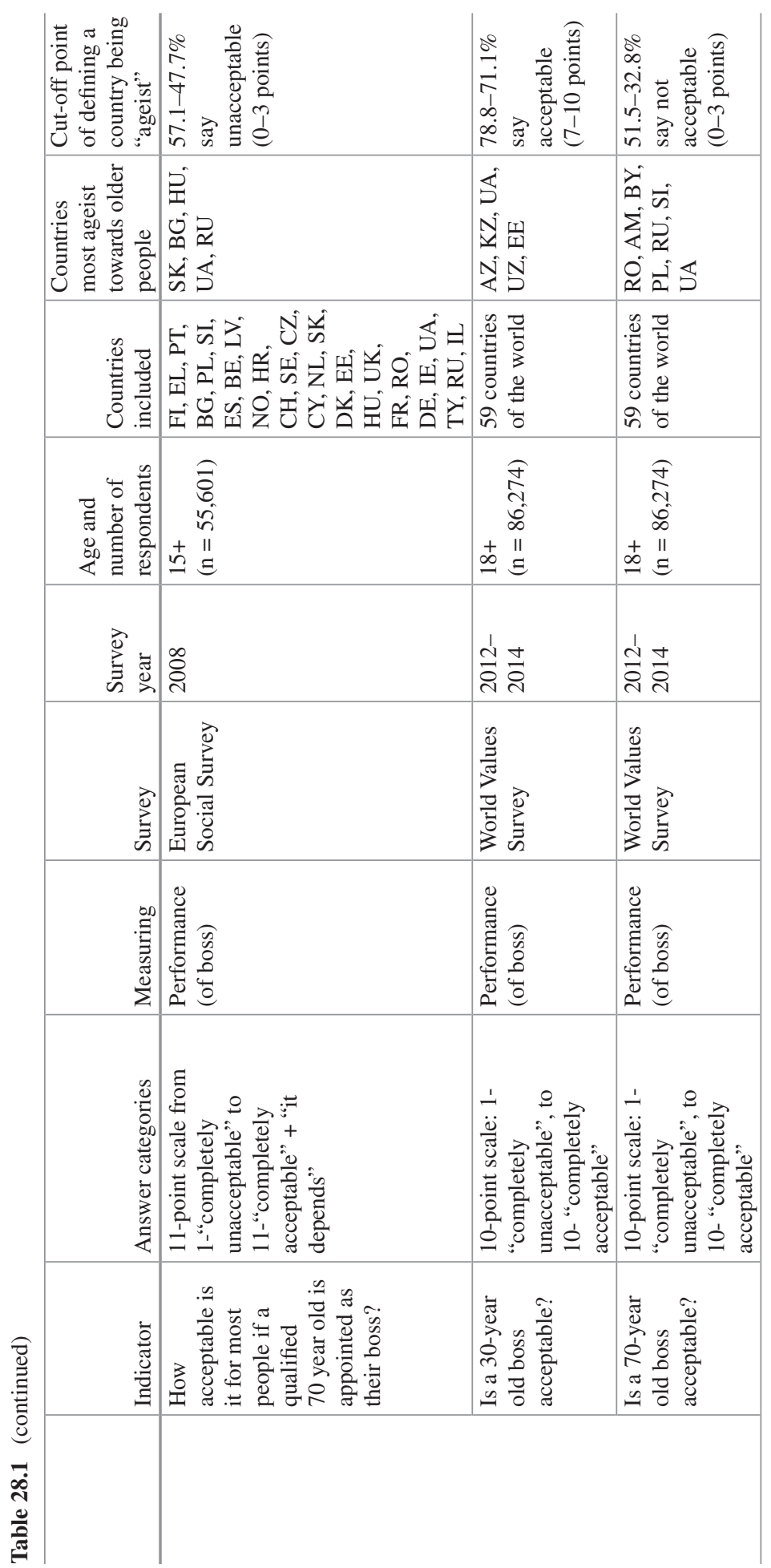




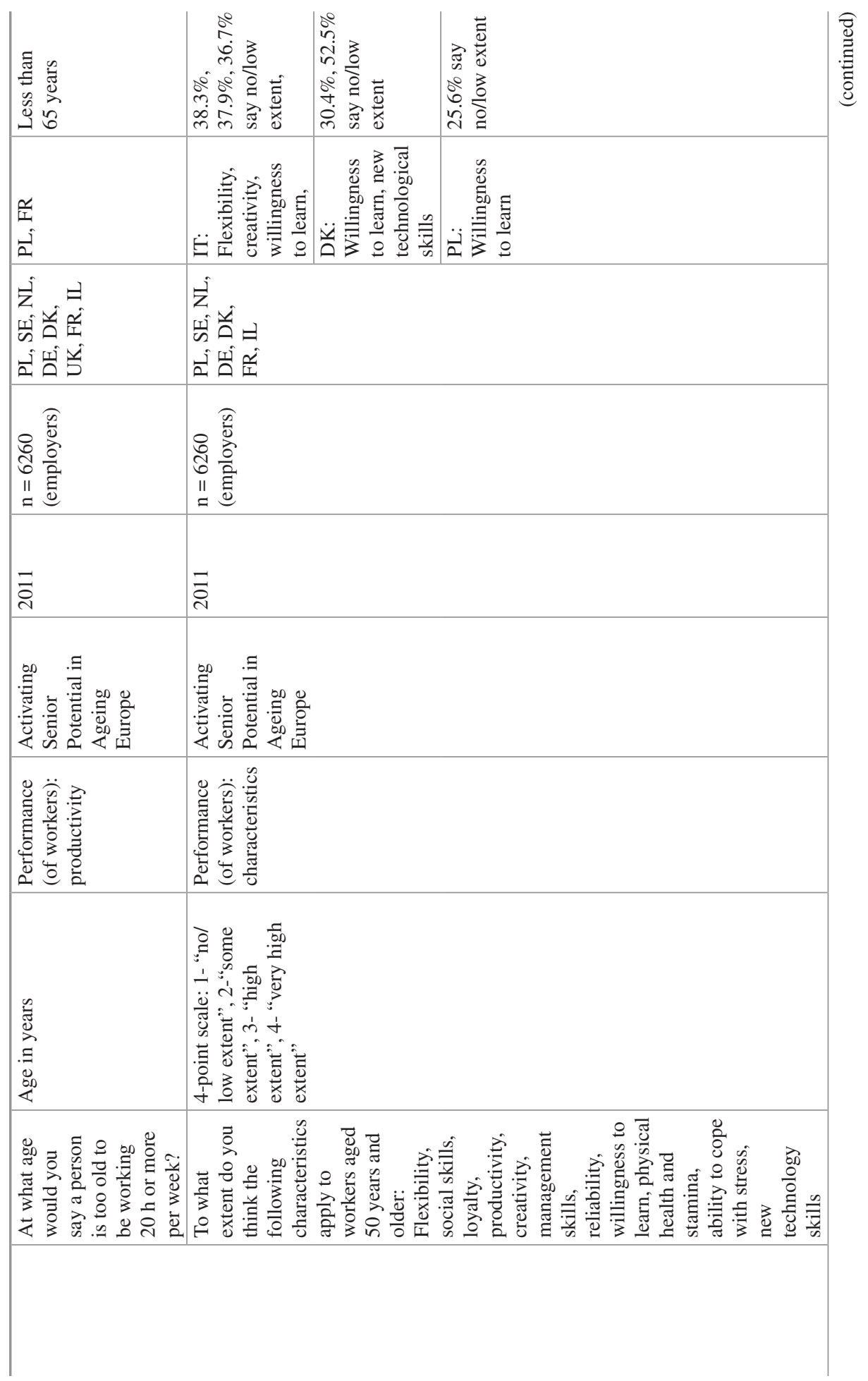




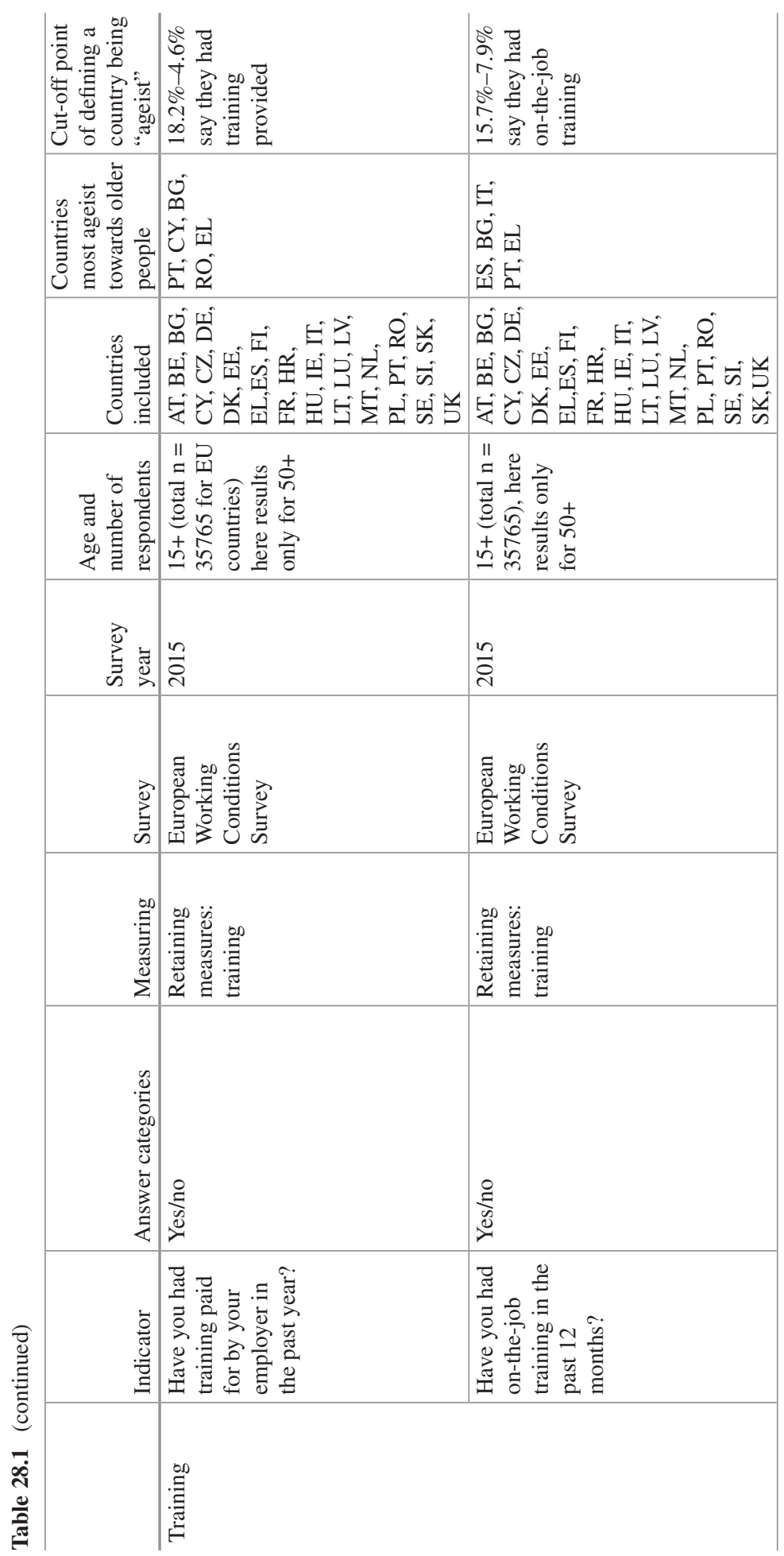




\begin{tabular}{|c|c|}
\hline 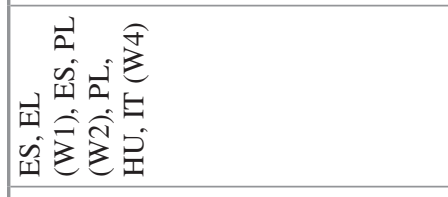 & 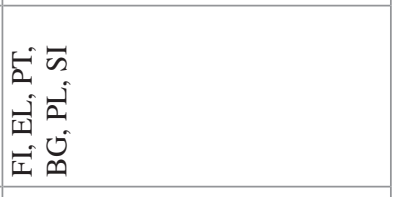 \\
\hline 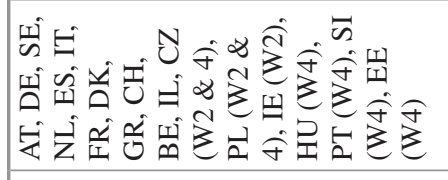 & 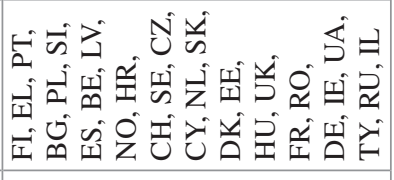 \\
\hline 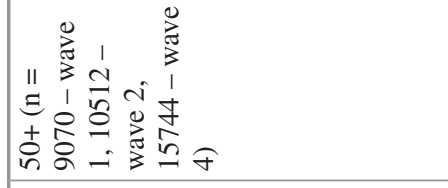 & 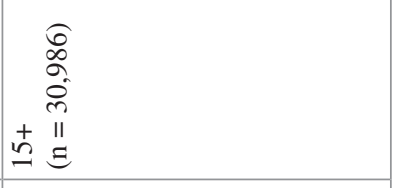 \\
\hline 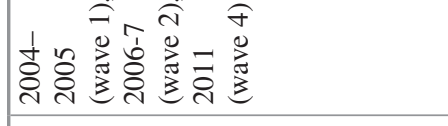 & 文 \\
\hline 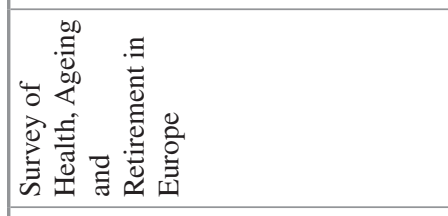 & 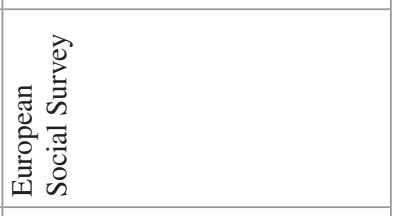 \\
\hline 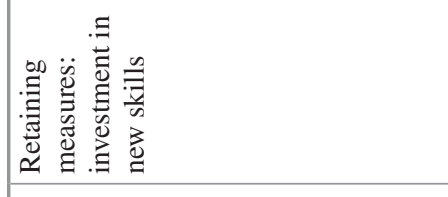 & 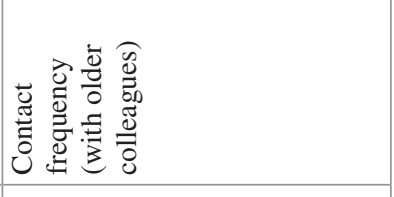 \\
\hline 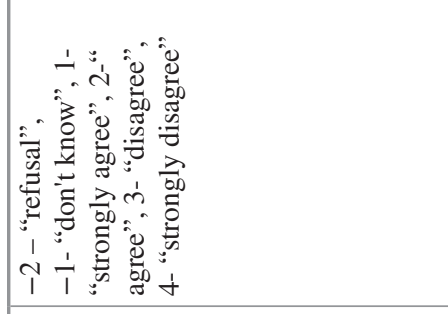 & 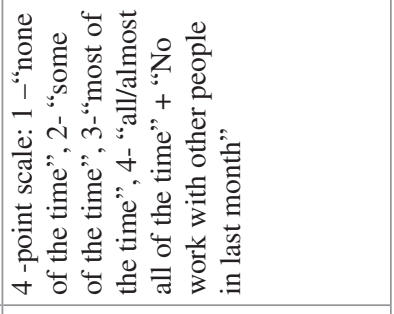 \\
\hline 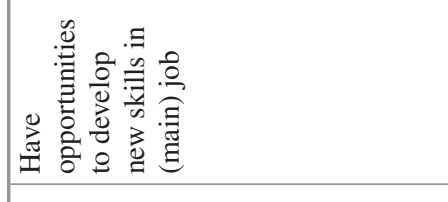 & 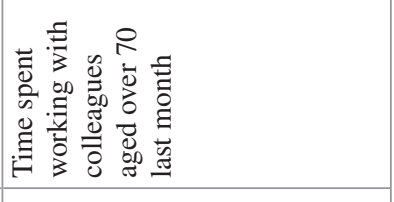 \\
\hline & 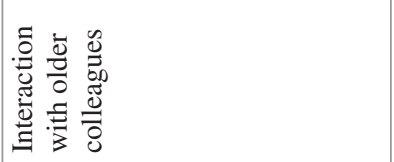 \\
\hline
\end{tabular}




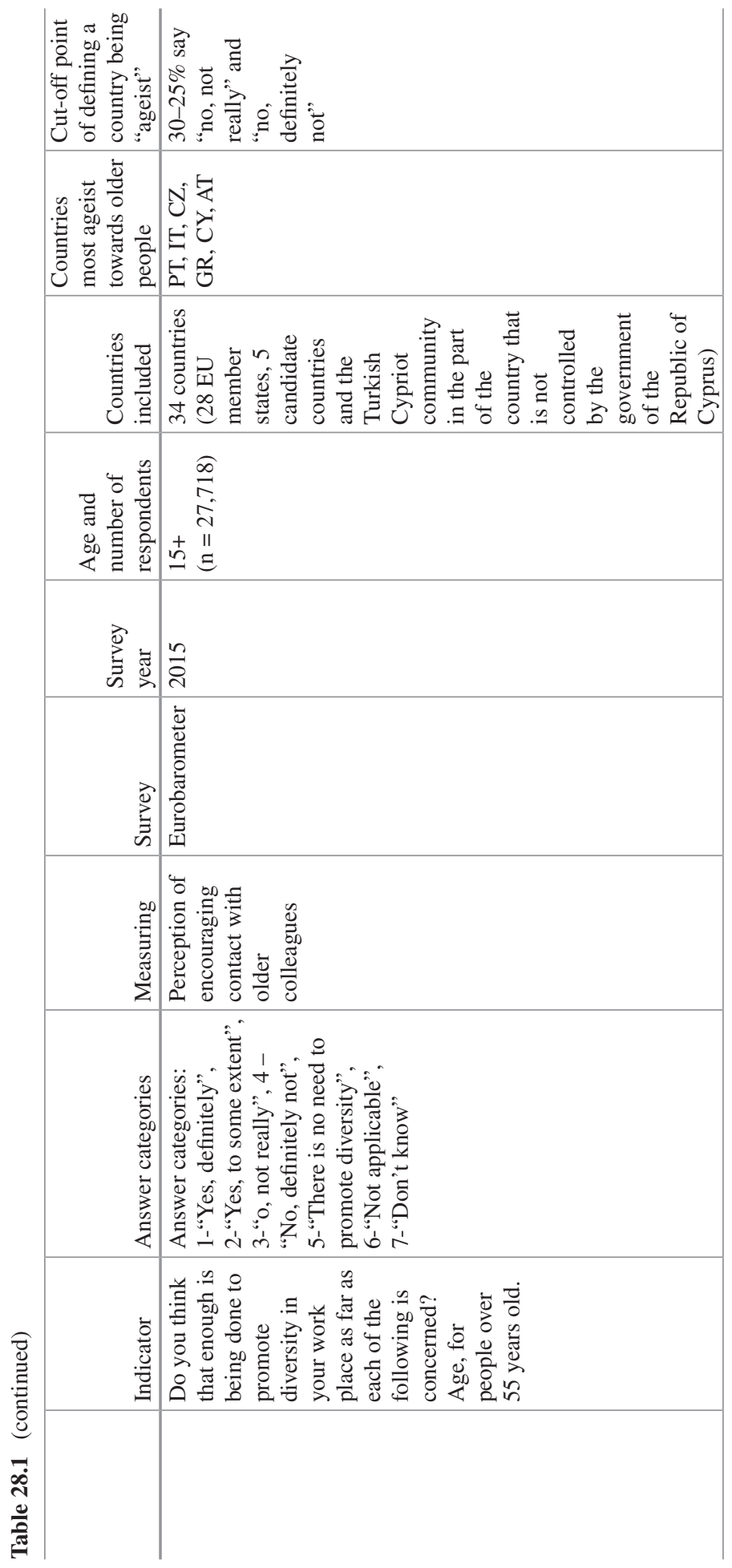




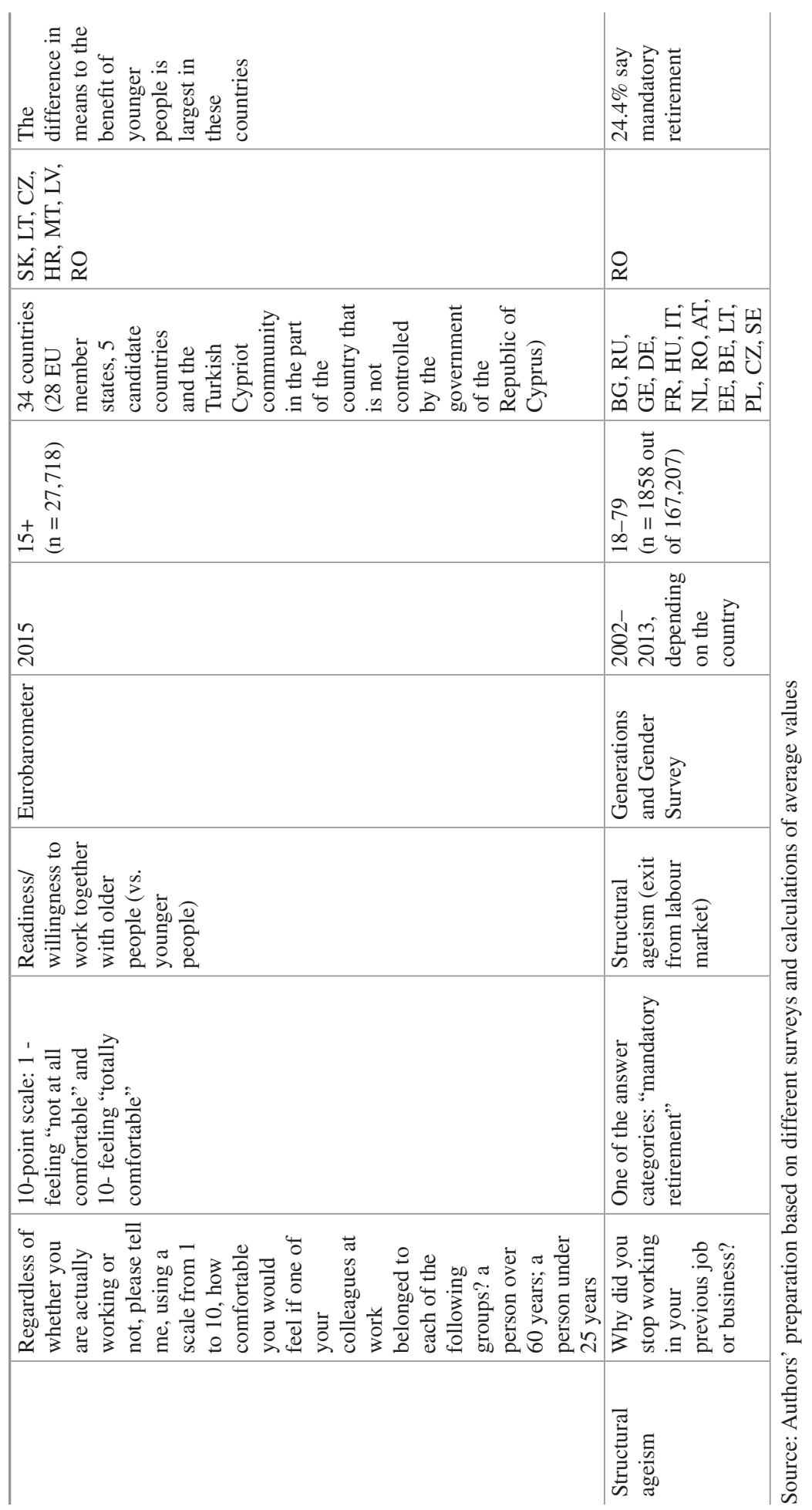


behaviour or attitudes in others. Hence, differences in the results might partly be related to this nuance. In the question that asked about people's perceptions of employers' ageist behaviours, Finland, Greece, and Portugal were shown to be the countries that were most concerned about employers preferring people in their $20 \mathrm{~s}$ over people in their 40s. The question that asked about a person's own ageist views showed that Georgia, Bulgaria, and Russia were the most ageist.

The indicator that we used from Eurobarometer ("In ([name of country], when a company wants to hire someone and has the choice between two candidates with equal skills and qualifications, which of the following criteria may, in your opinion, put one candidate at a disadvantage? The candidate's age, if he or she is over 55 years old?"- which was one of the possible answer categories) can be used as a measure of attitudes towards hiring older people. The highest percentage of people reporting this criterion was found in the Netherlands, Finland, and Cyprus. On the other end were Great Britain, Italy, Croatia, Poland, and Ireland. This indicator may have measured awareness of disadvantage by age rather than actual perceptions, attitudes, or experiences of ageism in the labour market.

Two questions from the European Social Survey that are categorised under recruitment/retention can be indicators of how people of different generations are perceived from an economic perspective. These questions ask about the contribution of younger (20s) and older (70s) people to the economy, but in two separate questions, thus not explicitly opposing young and old within a single indicator. However, when we compared the results from the two questions, we were able to identify countries in which respondents demonstrated ageist attitudes as those that had a high percentage of people who thought that people in their 20s contribute to the economy a great deal and a high percentage of people who thought that people in their 70s contribute little. The countries that scored high on both indicators were Russia and Latvia.

\subsubsection{Performance}

One question in the European Social Survey and one question in the World Values Survey asked about the acceptability of having a 70-year-old boss. The World Values Survey question was accompanied by a note indicating that countries may change the wording from " 70 " to "over 60 " if the $70+$ population is small. (The list of countries that changed the wording can be found from additional survey methodology or metadata documentation). The results of both surveys show that Slovakia, Bulgaria, Hungary, Ukraine, Russia, Slovenia, Romania, and Armenia were the least accepting of this situation. Finland also scored quite high in terms of being less accepting of having an older boss, although they remained within the margins of the standard deviation of the mean. In the Finnish case, it is possible that the fixed retirement age of 68 and mandatory retirement age of 67 for some public service occupations (O'Dempsey and Beale 2011) have some influence on the answers. Azerbaijan and Ukraine (followed by Kazakhstan, Uzbekistan, Estonia, Belarus, 
Romania, Russia, and Georgia within the standard deviation margin) showed correspondingly the highest proportions of people accepting a 30-year-old boss. Some non-European countries, such as Colombia, Egypt, Mexico, Qatar, Brazil, and Peru have reported values of the same magnitude.

One question from the World Values Survey measured attitudes about people's performance ("Companies that employ young people perform better than those that employ people of different ages"), and can be used as one of the measures of productivity expectations or prejudice. It is important to bear in mind that this question, similar to the Eurobarometer question about age being a potential disadvantage in recruitment/retention, addressed the ageist views of the respondents themselves, not their experiences or perceptions of ageism in others. Respondents from Azerbaijan, Kyrgyzstan, and Cyprus reported the most ageist attitudes in this indicator, following, on a global level, Ghana, Egypt, India, Turkey, and South Korea. Also, this was the only indicator among performance measures that opposes "young people" and "people of different ages." However, due to its ambiguous wording the question might measure attitudes of opposing performance of "young people" and "people of all ages", and not so distinctively "young people" and "old people".

Two questions from the Activating Senior Potential in Ageing Europe survey (Conen et al. 2011b) measured employers' ageist perceptions or attitudes. One of them was an indicator of attitudes about older adults' productivity or work ability ("At what age is a person too old to be working $20 \mathrm{~h}$ or more per week?"). This question was different from other indicators as it did not pre-define an age, but rather let the respondent (employer) define it. Polish and French employers reported the most ageist attitudes according to this indicator, as the mean value of answers was the lowest for respondents in these countries, i.e., below 65. The second item mapped a number of characteristics that are attributed to older workers (aged 50 or above): "To what extent do you think the following characteristics apply to workers aged 50 years and older (1 - " no/low extent", 2 - "some extent", 3 - "high extent", 4 - "very high extent"): flexibility, social skills, loyalty, productivity, creativity, management skills, reliability, willingness to learn, physical health and stamina, ability to cope with stress, new technology skills". Employers in Italy reported the most ageist attitudes: a larger share of these employers thought that flexibility, creativity, and willingness to learn did not apply to workers aged 50+. In Denmark and Poland more employers felt that older workers have no motivation to learn, and that they lack new technological skills.

\subsubsection{Training}

A number of questions addressed the workplace training of older adults. These questions can be used as sub-indicators for both retention and performance. Investing in older workers' training and skill renewal can improve their performance, which is especially important in societies where the general population as well as the workforce is ageing. These indicators could be used as measures of 
ageism regarding older people's performance enhancement at work. However, they could also be used as indicators of retaining practices. Through training that improves the performance of the existing workforce in an organisation, the retention of the workforce should also improve.

Two questions targeting employees and self-employed people from the European Working Conditions Survey showed that in Cyprus, Bulgaria, Romania, Bulgaria, Spain, Greece, Italy, and Portugal, a fairly small number (approximately 15\%) of workers aged 50 and above reported having received paid or on-the-job training.

The Survey of Health, Ageing and Retirement in Europe ${ }^{3}$ included a self-reported indicator of opportunities of training on the job of currently employed people. This was identified as a measure of investing in older workers'(aged 50+) performance as well as of workforce retention. According to this indicator, over $40 \%$ of employed people above the age 50 in Spain (in 2004 and 2006), Greece (in 2004), Poland and Hungary (both in 2011), and over 50\% in Poland in 2006 reported not having had training opportunities.

\subsubsection{Interaction with Older Colleagues}

Three indicators were classified as measures of interaction with older colleagues. The Eurobarometer survey (2015) asked the following question: "Do you think that enough is being done to promote diversity in your work place as far as each of the following is concerned?" Options included, "Age, for people over 55 years old". Portugal, Italy, the Czech Republic, Greece, Cyprus, and Austria had the highest percentage of people reporting that diversity was not being promoted in terms of having people 55 and older in the workplace. The option, "There is no need to promote diversity," was not included in the calculation of these outcomes, because the interpretation of this option includes ambiguity, and might therefore go beyond ageism towards older people only. However, we see that it could be considered as an answer category indicating ageism as well. If that option was to be taken into account, the countries with the highest percentage indicating ageism in that measure would include Bulgaria, Italy, Portugal, Poland, Greece, and the Czech Republic. In addition to interaction with older colleagues, this indicator might be used as a measure of ageism in hiring practices, but more specific information is needed to complement this.

We included a second question from the Eurobarometer survey: "Regardless of whether you are actually working or not, please tell me, using a scale from 1 to 10 , how comfortable you would feel if one of your colleagues at work belonged to each of the following groups: a person over 60 years; a person under 25 years." This question can be used as an indicator of readiness or willingness to work with older

\footnotetext{
${ }^{3}$ Data from wave 1 (2004-5), 2 (2006-7) and 4 (2011) were included in this overview. Data from the most recently available wave 5 (2013) yielded numbers of cases that were too low to be analysed by each country.
} 
people (vs. younger people). In general, the means for both age groups were quite high, but some countries indicated a lower mean of comfort for working with people aged below 25 years. We decided to calculate the difference in means between these indicators of different age groups to get a better idea of which countries had the largest split in acceptance of older and younger colleagues. The following countries showed the largest difference, indicating a greater comfort with younger than with older colleagues: Slovakia, Lithuania, the Czech Republic, Croatia, Malta, Latvia, and Romania. Interestingly, the means for being comfortable with younger and older colleagues were the same both in Denmark and Spain, indicating that egalitarian attitudes are more common in these two countries.

The European Social Survey asked how much time respondents had spent working with someone over 70 in the month prior to the interview. This indicator is a good measure of contact frequency between different age groups. Contact with older colleagues is an important factor in improving attitudes towards older people (Henkens 2005). Most people in all the countries surveyed did not have contact with colleagues over 70 in the workplace, probably as a result of most people retiring before that age. The largest proportion of people not having spent any time with colleagues over 70 were found in Finland, Greece, Portugal, Bulgaria, Poland, and Slovenia. The highest proportion of people having spent at least some time with colleagues over 70 were in Israel, Ireland, and France. Israel actually had the largest proportion of respondents saying they had spent most of their time $(6.7 \%)$ or all/ almost all of their time (5\%) working with colleagues aged 70 and over. In addition to ageist attitudes, the results are probably related to other factors, such as state policy (fixed retirement age), distribution of the population by fields of economic activity within countries, and life expectancy. Further analysis could deconstruct the exact conditions and causes shaping interaction with older colleagues: how much can be attributed to the ageist attitudes of employees, employers, and policymakers, and how much can be attributed to other factors, such as policies of mandatory retirement.

\subsubsection{Structural Ageism}

The mandatory retirement indicator is an explicit measure of structural ageism that might be a barrier for people to continue working. According to this self-reported measure from the Generations and Gender Survey, Romania has a large proportion $(24.4 \%)$ of people leaving their job due to mandatory retirement. It would be useful in future surveys to ask whether people would have continued working if mandatory retirement did not exist or if they had the chance to work past retirement age. Hence, a combination of willingness to continue working and the actual exit age would give a more informative idea of the extent of ageism. Otherwise, the single self-reported measure in its current form might just reflect the existence of an official retirement age, where causality might in fact run the other way, with the official retirement age impacting people's attitudes. 
Table 28.1 presents the most relevant survey questions. We decided to group the measures by the topic or theme they cover, for a total of five groups. Many of the questions capture attitudes, opinions, and perceptions with a scale measurement, such as a 4-point or 11-point Likert scale. However, even variations in the wording of similar measurements can lead to variations in output in terms of the countries' ranking on ageism in the labour market. Thus, results may reflect cultural differences in understanding and interpreting ageism. The importance of cultural contexts is discussed below.

\subsubsection{Other Potential Indicators of Ageism in the Labour Market}

The Survey of Health, Ageing and Retirement in Europe has several indicators that could be used as measures of ageism in the labour market (e.g., having a short-term or permanent contract, opportunities to develop new skills, and evaluation of prospects for job development). However, the most recently available wave of this survey (wave 5, 2013) had a low number of cases for most of these indicators. Coupled with a longitudinal methodology that maps each individual's various spheres of life events and characteristics every 2 years, the survey could potentially be a valuable source for studying ageist attitudes and experiences at the individual level. However, the ageing and attrition of the sample in longitudinal surveys often leads to a decrease in the number of cases (in this case employed older adults) available for analysis after a few waves.

In the European Union Labour Force Survey, one indicator was spotted that could be used as a measure of ageism in recruitment. The question, "Why did you not take the job when offered?", was followed by a number of options, including, "The employer wanted someone younger." This question was in the Estonian LFS questionnaires from 2009-2014 (question H24).

The European Company Survey included two potential indicators, one of which is an indicator of ageism in hiring practices: "Could you please tell me, for this establishment, the number or percentage of employees who... are older than 50 years of age?" The second question, which could be used as an indicator of attitudes regarding older employees' training practices or of an ageist behaviour ("Please tell me for each of the following groups of employees whether or not their needs for further training are systematically checked at regular intervals"), included "Older employees" as one of the potential answers (question MM562, Management Questionnaire, 2009).

The European Working Conditions Survey had indicators of potential ageist experiences at the workplace, such as: "Over the past 12 months at work, have you been subjected to any of the following?", followed by a number of options, including "Age discrimination" (Q65/72 in the 2010 and 2015 questionnaires); and "Since you started your main paid job, have you been subjected at work to any of the 
following?" (Q72 in the 2010 questionnaire only), also followed by a range of options, including "Age discrimination".

Activating Senior Potential in Ageing Europe had a number of potential indicators of ageism in the labour market, two of which we mention here: "At what age would you say a person is generally too young to retire permanently?", as an indicator of ageism towards younger ages; and "To what extent do you think the following characteristics apply to workers aged less than 35 years: flexibility, social skills, loyalty, productivity, creativity, management skills, reliability, willingness to learn, physical health and stamina, ability to cope with stress, new technology skills?", which could be used as an indirect indicator or as a validation of ageism towards older people because it does not use a specific term for older people in the wording.

\subsection{Evaluation of the Findings}

This paper identified measures of ageism in the labour market and tested their performance in cross-country comparisons. The comparative analysis was done with descriptive methods only, so the conclusions on country differences should be tested in the future with more rigorous analyses. Our discussion in the current section focuses on the topics or themes of measures, the target population of indicators and surveys, the wording of questions (especially with regard to the definition of old age), and each survey's usefulness for researching ageism in the labour market.

The measures identified in international cross-country surveys cover a broad scope of aspects of ageism in the labour market. Some measures indicated acceptance of older people as colleagues or as bosses, asking about frequency or availability of contact with older colleagues, about perceptions of employers' preferences in recruitment or performance of older adults, about qualities attributed to older people, and also about practices to improve older people's performance, training, and retention. There was also one indicator addressing the experience of structural ageism. In general, we divided the indicators into five broad groups based on which aspect of ageism in the labour market they measured:

- Recruitment and/or retention of older people,

- Performance of older workers,

- Training,

- Interaction with older colleagues,

- Structural ageism.

The recruitment/retention and performance indicators were the most widespread.

The target populations of the indicators and surveys examined in this chapter are generally defined by the survey sampling, not by a specific question. However, it is possible that some survey questions targeted specific respondents through routing. One question in the Eurobarometer survey specified that all survey respondents should reply regardless of the employment situation of the respondent. The 
Eurobarometer survey, the European Social Survey, the World Values Survey and the Generations and Gender Survey target the general adult population, with only the Generations and Gender Survey having an upper age limit (79). Some surveys specifically focus on older people (50+ in the Survey of Health, Ageing and Retirement in Europe), and some more generally on the working age population or working environment of employees and self-employed people (Labour Force Survey, European Working Conditions Survey). Company and employer surveys (European Company Survey, Activating Senior Potential in Ageing Europe) can be very valuable sources for studying employers' perspectives, attitudes, and practices because these are positions where ageist practices are often implemented.

There are variations in how "old age" is defined in the measures. Some use specific age indicators (e.g., 20s, 30s, 40s, 50 or above, 70) whereas other indicators are more general (e.g., "young," "old," "different ages"). However, most of these measures do not give information about what the respondents themselves consider "old," and therefore the results may be a reflection of a combination of factors. Only one question in the Activating Senior Potential in Ageing Europe survey asked employers to define the age at which an employee would be considered too old to work $20 \mathrm{~h}$ or more per week. In some cases, for example in the World Values Survey, differences in demographic structure are taken into account and countries have the option to change the wording of the question (from "70" to "over 60") if there are too few people in the older age groups. This is a good example of taking into account demographic trends and country context in measuring age discrimination, as well as of the perception of when old age starts (possibly often associated with eligible retirement age). This is also something for researchers to take into account when comparing different countries. In some cases, such as in the Eurobarometer interaction indicator, it is possible to combine different age groups for comparison.

It is not clear to what extent questions that specify a certain age or age group measure purely ageist attitudes. The results may reflect various aspects of the labour market, such as participation levels, qualification requirements, economic circumstances, health and life expectancy, and so on. In general, based on our descriptive overview, several Eastern and Central European countries emerge as most ageist based on the studied indicators-especially Russia, Poland, and Slovenia, followed by Bulgaria, Romania, and Ukraine. Some of these countries had a relatively low retirement age (60 for men and 55 for women) in the 1990s and in some cases even into the early twenty-first century (De Castello 1998; Puur 2000). Rapid population ageing and the transition from a planned economy to a market economy have occurred in these societies within a relatively short period. The economic restructuring during the transition period resulted in job losses that particularly impacted the older population, as new types of knowledge and experience were suddenly required (Puur 2000; Nugin et al. 2016). Therefore, several Eastern and Central European countries might have had less time to develop positive age-related attitudes, or in some cases might have placed a higher value on young people in the workforce that still holds today. Consequently, older people's potential, including in terms of loyalty, reliability, and experience, in the labour market may not yet be valued in a 
similar way as in some Nordic or Western countries. When comparing countries, contextual and historical backgrounds play an important role, especially the significant societal transformations that have occurred in several Eastern European countries since the 1990s.

Western and Northern European societies also have some ageist manifestations. Finland in particular emerged as a somewhat ageist country. This might indicate structural problems in the labour market, but it can also signify a high awareness of ageism in this country. Israel seems to be a competitive country where older people need to or want to work beyond the retirement age (or a very heterogeneous country with different attitudes and practices regarding older workers in different communities), but did not appear necessarily to be ageist based on our findings. A large proportion of people in Israel were concerned that people in their 20s were preferred by employers over those in their 40s. At the same time, a large proportion of people said that young people actually contribute to the country's economy a great deal. Also, Israel had the largest proportion of people who said they had spent time working with colleagues aged 70 or over, indicating a high frequency of contact between different age groups in the workplace. Israel's retirement age of 67 is relatively high compared to most other countries, which might influence the possibility of spending time with older colleagues in the workplace.

The Activating Senior Potential in Ageing Europe survey proved to be very useful in our study of ageist attitudes in that it pointed to potential problems with employers' attitudes in some Western and Nordic countries. We found that Italy had the largest proportion of employers who hold negative views about the characteristics of older adults. However, the Activating Senior Potential in Ageing Europe survey only included eight European countries, one of which was in Eastern Europe (Poland). Also, this survey was only carried out once, which does not allow for the assessment of changes in attitude over time. The results from the European Working Conditions Survey showed that a fairly small number of workers aged 50 and older have received training in Southern European countries such Portugal, Cyprus and Greece, but also including Bulgaria and Romania.

Questions in which the wording opposed different age groups in a single question-for example, "How worried that employers prefer people in their 20s rather than 40 or older?" seemed to work in a similar way to separate questions that asked about different age groups (for example, "Is a 30 -year old boss acceptable?" and "Is a 70-year old boss acceptable?"). However, from the indicators observed in this paper, the questions that asked specifically about respondents' preferences of one age group over another seemed to create an explicit outcome of ageism. This might be because the wording of these questions presented an inevitable opposition that was necessarily reflected in the answer. Respondents' perceptions of their employers' attitudes might also lead to some confusion in the results because the answers may be dependent on overall satisfaction with the working environment (GarcíaMainar et al. 2015) or overall satisfaction with colleagues (Hombrados-Mendieta and Cosano-Rivas 2013). Therefore, it might be more accurate to rely on employers' self-reports of their attitudes. One question's wording can be understood or interpreted ambiguously by respondents ("Companies that employ young people 
perform better than those that employ people of different ages"). Therefore the performance of this indicator as a measure of ageism specifically towards older people requires additional validation.

The European Social Survey and the World Values Survey are both general attitudinal surveys. Unfortunately, they have not included questions about ageist attitudes in the labour market context on a regular basis. Data on ageist attitudes gathered at one point in time do not give any information on the dynamics of the attitudes, how they change, improve, or worsen over time. Ideally, these dynamics could be measured longitudinally, as they are in the Generations and Gender Survey. In the Generations and Gender Survey, the relevant measures were included in waves 1 and 2. In a number of countries, many of the same people were interviewed in both waves. Therefore, using longitudinal methodology would give the best picture of change in attitudes over time.

Even though we identified some possible indicators of ageism in the labour market from the Survey of Health, Ageing and Retirement in Europe, most of these indicators did not have enough cases per country for generalisation. This is because some of the specific questions of the survey only targeted employed individuals, which means that the number of employed people per country included in the Survey of Health, Ageing and Retirement was too low to provide representative information pertaining to ageism in the labour market (at least in wave 5). This may be reflective of low labour force participation levels among the 50+ population in several countries, and thus itself may be a manifestation of ageism in the labour market. Alternatively, the problem may lie in attrition of people over time in panel studies.

The Generations and Gender Survey could be a useful source for studying ageism in the labour market, especially as it had one indicator of structural ageism. However, to be able to evaluate the effect of mandatory retirement as ageist, more measures need to be added to the analysis, such as willingness to work above the mandatory retirement age, which is highly dependent on job type, education, and broader cultural values on the individual level. One of the downsides of using the Generations and Gender Survey is that the fieldwork has been carried out over a long period of time (2002-2013). Hence, period effects, such as changes in political, legislative, and economic settings that may shape ageist attitudes or practices in the labour market may not be captured well.

\subsection{Taxonomy and Recommendations for Researching Ageism in the Labour Market}

This chapter examined indicators that asked about ageism-related beliefs, attitudes, and perceptions regarding the labour market. We disregarded more general ageist behaviours, attitudes, and feelings that were not related to the labour market. The 
Table 28.2 Taxonomy of measures of ageism in the labour market

\begin{tabular}{l|l|l|l}
\hline Topic/theme & Perspective & Defining (old) age & $\begin{array}{l}\text { Target population of surveys or } \\
\text { questions }\end{array}$ \\
\hline Recruitment/retention & View & $\begin{array}{l}\text { Opposing different age } \\
\text { groups }\end{array}$ & $\begin{array}{l}\text { General population vs. targeted } \\
\text { population }\end{array}$ \\
\hline Performance & Value & Specific age & Age limit \\
\hline Training & Attitude & Asking to define age & \\
\hline $\begin{array}{l}\text { Interaction with } \\
\text { colleagues }\end{array}$ & Perception & & \\
\hline Structural ageism & Experience & & \\
\hline
\end{tabular}

Source: Authors' preparation based on the overview done for this chapter

purpose was to map indicators of ageism in the labour market from existing largescale social surveys that are representative of countries' total populations, and that were carried out using internationally comparable methodologies. Table 28.2 presents a taxonomy of the studied measures (see Table 28.2). The measures, the taxonomy, and the surveys included in this analysis should not be taken as an exhaustive list. All of the surveys included here are carried out in several countries. Most of the observed indicators were measured only at one point in time, so change over time from an international perspective is not addressed in Table 28.2, but it is discussed in the text.

\subsection{Age: What Is Old?}

The age limits included in some survey questions were very broad. As a general rule, the definition of "old" depends on the country's cultural, social, and historical background. Some surveys or questions pre-defined "old", for example by limiting the age of the population that responds to the specific survey or question. Only one question, from the Activating Senior Potential in Ageing Europe survey, asked employers to specifically define old age ("At what age would you say a person is too old to be working 20 hours or more per week? "). Some outcomes of these measures may have multiple interpretation options in addition to indicating ageism towards older people in the labour market. For example, in the indicator that asked respondents specifically about people in their 20s and people in their 40s, the outcome may reflect a variety of situations, experiences, and policies relating to the educational system, labour market rigidity, occupation, and economic sector specificities of people from different age groups. To help mitigate this confusion, the definition of "old" should be very transparent or should be made very specific when ageism measures are being developed as well as when data is analysed. In surveys that allow for country-specific variations (as in the case of the World Values Survey), researchers should use additional documentation to research country information and should report such differences in measurements in their own research reports and articles. 
When surveys include separate questions with different age groups specified in the questions (for example: "Is a 30-year old boss acceptable?" and "Is a 70-year old boss acceptable?"), such indicators should be both used and compared in analyses.

\subsection{Target Population}

It is important to differentiate between the perspective of employees and employers when studying ageism in the labour market. When using surveys, the occupation of the respondent and the sector in which he or she is employed should be among the controlling factors. As employers are largely responsible for shaping organisational cultures and practices through communication (Henkens 2005; Solem 2015), specific surveys that target employers and would be conducted regularly might be especially useful. Some indicators not specifying a target population may be more suitable for assessing public opinion on ageism in the workplace.

\subsection{Development over Time}

All the indicators included in this study were measured only at one point in time. Regular measurements are needed to assess changes in attitude over time, the influence on attitudes of younger people entering the labour force, and the impact of policy or organisational reforms on attitudes. Longitudinal studies might provide the best opportunity to assess changes in ageist attitudes at the individual level, which might be influenced by personal or policy factors. The same might apply to employers' surveys.

\subsection{Context Matters}

Large international social surveys provide an opportunity to combine information from different spheres in a person's life; therefore, researchers of ageism indicators should make maximum use of existing surveys and the rich information within them. In addition to including indicators of overtly ageist attitudes, other more or less related events and characteristics should be controlled for, such as occupation, work history, and other related perceptions and attitudes. Specifically, satisfaction with life, satisfaction with the work environment, and satisfaction with colleagues can be seen as general proxies for subjective well-being (Muffels and Headey 2013), as well as subjective well-being in the labour market context (Tay and Harter 2013). 
Therefore, including these measures in research of ageism in the labour market may help explain ageist experiences of employees to an important extent. Studies should be able to address causality issues and to deconstruct the effects of attitudes, perceptions, organisational practices, employers' financial resources, structural barriers, and other factors influencing older adults' labour force participation and experiences.

Countries' contextual and historical backgrounds should be elaborated on in analyses of ageism in the labour market. As mentioned above, this may help to supplement information on demographic development (for example, regarding population ageing), how older people are seen in general in society, the context for developing certain attitudes, and how institutional settings have changed over time to accommodate these developments. Our descriptive analysis is only the first step in mapping ageism in the labour market on an international level. Future studies could aim to disentangle the relationship between measures and country contexts with regard to ageism in the labour market. With population ageing and transformations in the way work is done, ageism is an increasingly important topic for researchers and policymakers to address.

\subsection{Limitations}

This overview only mapped self-report measures that were mostly about attitudes, perceptions, and experiences of ageism in the labour market from quantitative social surveys. We acknowledge that some of the outcomes or country rankings might be explained by other factors, such as occupation or economic sector, the working environment, individual countries' policies and legislation, countries' historical and social contexts, and so on. For example, the measure we list under structural ageism (mandatory retirement as a reason for stopping work") can be seen to measure several things at the same time: the country's mandatory retirement age, respondents' willingness or unwillingness to work, and other factors. Therefore, future analysis should not only examine a single indicator. In addition, it would be useful to map "real-life data" or "hard data"- that is, measures of non-perception aspects of ageism in the labour market. These measures could include actual number of older workers in an organisation, number of trainings provided for older workers in comparison to younger people and their correspondence to the needs of people, contract and salary comparisons, and so on.

Another limitation of our study is that we have not included data with actual companies as the unit of analysis, capturing their hiring practices and promotion and retirement strategies. Including this data could give additional insights into the behaviour of employers. Even though such data have been collected, they are not currently publicly available. It was therefore not possible to include the results of these datasets in this overview. Finally, we carried out a descriptive analysis of 
available data, presenting an overview of measures from existing social surveys for the first time. This paper focused on identifying quantitative measures of ageism in the labour market and bringing out some basic descriptive results of country comparisons based on these measures. We recommend using these findings and measures from several surveys at the same time with more advanced statistical analyses to draw in-depth conclusions about ageism in the labour market.

Additionally, qualitative studies on ageism can provide in-depth information on the conceptualisation of age discrimination in employment (e.g., Roscigno et al. 2007) and the identification of practices that older individuals use, such as altering resumes, physical appearance, and language in order to increase their chances of being employed (Berger 2009). A number of studies offer insight into how to reexamine the hiring practices of employers or the retention of older workers (see, for example, Karpińska et al. 2011, 2013; Lazazzara et al. 2013). Data from qualitative studies on ageism in the labour market could be used to improve measures and surveys on this topic as well.

\subsection{Outlook}

There is an extensive collection of research tools for studying ageism in the labour market. Having data infrastructures in the form of international large-scale surveys makes it possible to conduct international comparative analyses of ageism in the labour market. Despite differences in the target population and in the wording of the questions, the existing surveys and measures provide a good opportunity to map attitudes and perceptions of ageism in the labour market with regard to recruitment, retention, performance, training of the workforce, and interaction with older colleagues. There are also ample opportunities for conducting rigorous internal validity tests of the indicators mentioned in this chapter.

The surveys examined in this overview allow information to be combined on several aspects of people's lives and their characteristics, which is highly advantageous. Cross-sectional analyses can be completed to assess change over time once the corresponding data become available.

\section{Appendix: List of Surveys}

Estonian Labour Force Survey (2009). Personal questionnaire. http://www.gesis.org/missy/files/ documents/EU-LFS/EE\%20LFS\%202009\%20Quest\%20Ind\%20Eng.pdf. Accessed 13 May 2016.

European Company Survey (2009). Management questionnaire. http://www.eurofound.europa.eu/ sites/default/files/ef_files/docs/surveys/ecs2009/questionnairemm.pdf. Accessed 13 May 2016. 
European Social Survey (2008). Round 4 Questionnaire. http://www.europeansocialsurvey.org/ docs/round4/fieldwork/source/ESS4_source_main_questionnaire.pdf. Accessed 16 May 2016.

European Working Conditions Survey, 6th survey (2010). Questionnaire. http://www.eurofound. europa.eu/sites/default/files/ef_files/surveys/ewcs/2010/documents/masterquestionnaire.pdf. Accessed 13 May 2016.

European Working Conditions Survey, 6th survey (2015). Questionnaire. http://www.eurofound. europa.eu/sites/default/files/page/field_ef_documents/uk_questionnaire.pdf. Accessed 13 May 2016.

Generations and Gender Survey (2003). Generations and Gender Survey Core Questionnaire for Wave 1. http://www.ggp-i.org/sites/default/files/questionnaires/GGP_QuestW1Core.pdf. Accessed 16 May 2016.

Generations and Gender Survey (2012). Generations and Gender Survey Core Questionnaire for Wave 2. http://www.ggp-i.org/sites/default/files/questionnaires/GGS_Wave2_ Questionnaire_V.2.0.pdf. Accessed 16 May 2016.

SHARE (2013). Wave 5 English generic main questionnaire. http://www.share-project.org/fileadmin/pdf_questionnaire_wave_5/SHARE_paperversion_5_4_10_en_GB.pdf. Accessed 16 May 2016.

World Values Survey (2012). Round 6 Questionnaire. http://www.worldvaluessurvey.org/ WVSDocumentationWV6.jsp. Accessed 16 May 2016.

\section{References}

Ayalon, L. (2013). Feelings towards older vs. younger adults: Results from the European Social Survey. Educational Gerontology, 39, 888-901. https://doi.org/10.1080/03601277.2013.7676 20

Berger, E. D. (2009). Managing age discrimination: An examination of the techniques used when seeking employment. The Gerontologist, 49(3), 317-332. https://doi.org/10.1093/geront/ gnp031

Blöndal, S., \& Scarpetta, S. (1997). Early retirement in OECD countries: The role of social security systems. OECD economic studies, No. 29, 1997/ II. http://www.oecd.org/eco/ growth/18378516.pdf. Accessed 19 July 2017.

Calasanti, T. M. (1996). Incorporating diversity: Meaning, levels of research, and implications for theory. The Gerontologist, 36(2), 147-156.

Conen, W., van Dalen, H., Henkens, K., \& Schippers, J. (2011a). Activating senior potential in ageing Europe: An employers' perspective (ASPA). Deliverable 12: Integrative international report on organisational surveys. The Hague: Netherlands Interdisciplinary Demographic Institute. http://www.aspa-eu.com/aspa_deliverables.htm. Accessed 13 May 2016.

Conen, W., van Dalen, H., \& Henkens, K. (2011b). Activating senior potential in ageing Europe: An employers' perspective (ASPA). Deliverable 1.1. Survey: Short report. The Hague: Netherlands Interdisciplinary Demographic Institute. http://www.aspa-eu.com/aspa_deliverables.htm. Accessed 13 May 2016.

Crenshaw, K. (1991). Mapping the margins: Intersectionality, identity politics, and violence against women of color. Stanford Law Review, 43(6), 1241-1299. https://doi.org/10.2307/1229039

De Castello Branco, M. (1998). Pension reform in the Baltics, Russia, and other countries of the former Soviet Union (BRO). Working Paper of the International Monetary Fund WP/98/11. http://www.imf.org/external/pubs/ft/wp/wp9811.pdf. Accessed 15 May 2016.

Duncan, C. (2003). Assessing anti-ageism routes to older worker re-engagement. Work, Employment \& Society, 17(1), 101-120. 
Duval, R. (2003). Retirement behaviour in OECD countries: Impact of old-age pension schemes and other social transfer programmes. OECD economic studies, no. 37, 2003//2. http://www. oecd.org/eco/growth/34561950.pdf. Accessed 19 July 2017.

García-Mainar, I., Montuenga, V. M., \& Navarro-Paniagua, M. (2015). Workplace environmental conditions and life satisfaction in Spain. Ecological Economics, 119, 136-146.

Henkens, K. (2005). Stereotyping older workers and retirement: The managers' point of view. Canadian Journal on Aging, 24(4), 353-366.

Hombrados-Mendieta, I., \& Cosano-Rivas, F. (2013). Burnout, workplace support, job satisfaction and life satisfaction among social workers in Spain: A structural equation model. International Social Work, 56(2), 228-246.

Jyrkinen, M., \& Mckie, L. (2012). Gender, age and ageism: Experiences of women managers in Finland and Scotland. Work, Employment and Society, 26(1), 61-77. https://doi. org/10.1177/0950017011426313

Karpińska, K., Henkens, K., \& Schippers, J. (2011). The recruitment of early retirees: A vignette study of the factors that affect managers' decisions. Ageing and Society, 31(04), 570-589.

Karpińska, K., Henkens, K., \& Schippers, J. (2013). Retention of older workers: Impact of managers' age norms and stereotypes. European Sociological Review, 29(6), 1323-1335.

Lazazzara, A., Karpińska, K., \& Henkens, K. (2013). What factors influence training opportunities for older workers? Three factorial surveys exploring the attitudes of HR professionals. The International Journal of Human Resource Management, 24(11), 2154-2172.

McNair, S. (2006). How different is the older labour market? Attitudes to work and retirement among older people in Britain. Social Policy and Society, 5(04), 485-494.

Muffels, R., \& Headey, B. (2013). Capabilities and choices: Do they make Sen'se for understanding objective and subjective well-being? An empirical test of Sen's capability framework on German and British panel data. Social Indicators Research, 110(3), 1159-1185.

Nugin, R., Kannike, A., \& Raudsepp, M. (2016). Generations in Estonia: Contemporary perspectives on turbulent times. Approaches to culture theory (Vol. 5). Tartu: University of Tartu Press.

O'Dempsey M., \& Beale A. (2011). Age and employment. European network of legal experts in the non-discrimination field. Supervised by Mark Freedland. European Commission Directorate General for Justice. http://ec.europa.eu/justice/discrimination/files/age_and_employment_ en.pdf. Accessed 19 July 2017.

OECD. (2013). Pensions at a glance 2013: OECD and G20 indicators. Paris: OECD Publishing. https://doi.org/10.1787/pension_glance-2013-en

Perek-Białas, J., \& Turek, K. (2012). Organisation level policy towards older workers in Poland. International Journal of Social Welfare, 21(s1), S101-S116.

Phillipson, C. (2004). Older workers and retirement: Critical perspectives on the research literature and policy implications. Social Policy and Society, 3(02), 189-195.

Puur, A. (2000). Changes in economic status of older population: The case of Estonia in the 1990s. Estonian Interuniversity Population Research Centre, RU series B no 42, Tallinn.

Roscigno, V. J., Mong, S., Byron, R., \& Tester, G. (2007). Age discrimination, social closure and employment. Social Forces, 86(1), 313-334.

Skirbekk, V. (2004). Age and individual productivity: A literature survey. Vienna Yearbook of Population Research, 2, 133-153.

Solem, P. E. (2015). Ageism and age discrimination in working life. Nordic Psychology, 68(3), 160-175. https://doi.org/10.1080/19012276.2015.1095650

Sonnet, A., Olsen, H., \& Manfredi, T. (2014). Towards more inclusive ageing and employment policies: The lessons from France, The Netherlands, Norway and Switzerland. De Economist, 162, 315-339. https://doi.org/10.1007/s10645-014-9240-x

Tay, L., \& Harter, J. K. (2013). Economic and labor market forces matter for worker well-being. Applied Psychology: Health and Well-Being, 5(2), 193-208. 
Taylor, P., \& Walker, A. (1998). Policies and practices towards older workers: A framework for comparative research. Human Resource Management Journal, 8(3), 61-76.

Turek, K., \& Perek-Białas, J. (2013). The role of employers opinions about skills and productivity of older workers: Example of Poland. Employee Relations, 35(6), 648-664.

Open Access This chapter is licensed under the terms of the Creative Commons Attribution 4.0 International License (http://creativecommons.org/licenses/by/4.0/), which permits use, sharing, adaptation, distribution and reproduction in any medium or format, as long as you give appropriate credit to the original author(s) and the source, provide a link to the Creative Commons license and indicate if changes were made.

The images or other third party material in this chapter are included in the chapter's Creative Commons license, unless indicated otherwise in a credit line to the material. If material is not included in the chapter's Creative Commons license and your intended use is not permitted by statutory regulation or exceeds the permitted use, you will need to obtain permission directly from the copyright holder. 